\title{
Concomitant mesiodens with cusps of carabelli on the upper first molars: a rare case report
}

\author{
Salma Babiker Idris Elhag' ${ }^{*}$, Ashraf Sidig Idris Abdulghani ${ }^{2}$ and Babiker Idris Elhag ${ }^{3}$ \\ ${ }^{1}$ Department of Orthodontics, University of Khartoum, Khartoum, Sudan \\ ${ }^{2}$ Department of Oral and Maxillofacial Surgery, University of Khartoum, Khartoum, Sudan \\ ${ }^{3}$ Private practice, Makkah, Saudia Arabia
}

\begin{abstract}
Variations in number, size, shape, position of teeth can occur separately or can occur concurrently together. An increase in the number of teeth is called hyperdontia and the most commonly found supernumerary tooth is the mesiodens which is found in the premaxilla between the two central incisors. The cusp of Carabelli is an extra cusp found on the palatal surface of the upper first molars. Both dental anomalies commonly occur separately and rarely occur together. In this case report we present a rare case of mesiodens with concomitant cusps of Carabelli.
\end{abstract}

\section{Introduction}

Dental anomalies are a common finding in dental practice. In the literature, the prevalence of dental anomalies ranges from 5.6\% to $74 \%$ [1]. Studies have shown that dental anomalies can occur separately or concomitantly with each other [2-4]. The association of supernumerary teeth with the cusp of Carabelli has not been well established in the literature.

Hyperdontia occurs due to the presence of extra teeth, namely, supernumerary teeth. A supernumerary tooth located in the midline is called a mesiodens, with its prevalence varying from 0.15 to $7.8 \%$ [5]. The occurrence of supernumerary teeth may be single or multiple, unilateral or bilateral, erupted or impacted, and in one or both jaws. Multiple supernumerary teeth are rare in individuals with no other associated diseases or syndromes [3].

The cusp of Carabelli was first discovered by Carabelli in 1842, who described it as a tubercle on the lingual surface of the mesiopalatal cusp of maxillary molars. The protuberant and cusp-formed structures have been named "positive cusps" while the furrow and pit formed, structures have been referred to as negative cusps. The positive cusp is demarcated occlusally from the parent molar by a well accentuated curved groove [6].

A thorough investigation of dental anomalies is essential to prevent malocclusion, periodontal problems, caries, and difficulties during tooth extraction and root canal treatment [1]. In view of the fact that treatment of mesiodens involves both surgical and orthodontic intervention, orthodontists therefore must be aware of the possible concomitant conditions detected with supernumerary teeth in order to obtain optimal aesthetic outcomes. In this report, a case of mesiodens with concomitant cusps of Carabelli is described.

\section{Case report}

A 12 year old male patient presented to our clinic due to an aesthetic problem related to his upper right central incisor which was mesiolabially rotated and overlapping the upper left central incisor. Intraoral examination revealed localized crowding in the anterior area due to a palatally positioned mesiodens which was not fully erupted. The patient had class 1 molars and class 11 canine relationships on both sides and class 11 divisions, 1 incisor relationship. Further investigation of the dentition revealed the presence of an additional dental anomaly which was the bilateral existence of prominent cusps of Carabelli palatal to both upper first molars (Figures 1-4).

\section{Discussion}

Tooth development is under the control of homeobox (HOX) genes consisting of a number of different mesenchymal regulatory molecules and their receptors, consequently, the mutation or interruption of tooth development by any etiological factor may result in dental anomalies [7].

Peck [4] coined the association of dental anomalies as dental anomaly patterns (DAP), where a single mutant gene may be responsible for more than one morphological or functional trait. Studies have

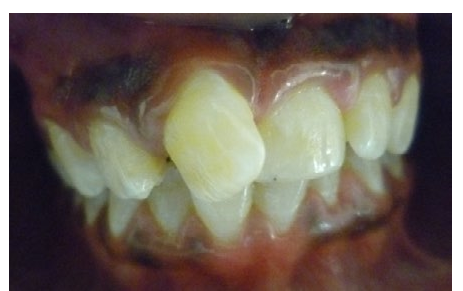

Figure 1. Labial Intraoral view showing rotated, mesiolabially angulated upper righ central incisor.

Correspondence to: Salma Babiker Idris Elhag, Department of Orthodontics, University of Khartoum, Khartoum, Sudan; E-mail: salmababiker2013@gmail.com

Received: November 06, 2015; Accepted: December 18, 2015; Published: December 21, 2015 


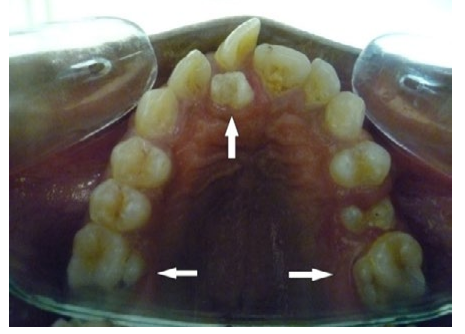

Figure 2. Upper occlusal view with arrows pointing to mesiodens behind the upper right central incisor and cusps of Carabelli on the palatal surfaces of the upper first molars.

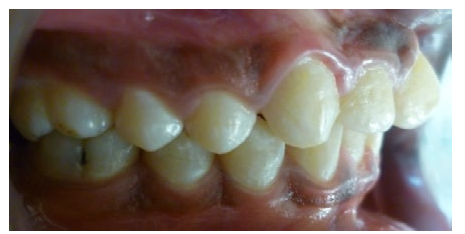

Figure 3. Right buccal view showing class 11 div 1 incisors, class 11 canines and Angle's class 1 molars.

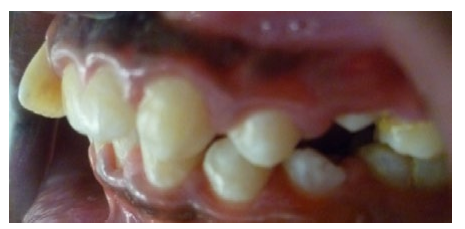

Figure 4. Left buccal view Right buccal view showing class 11 div 1 incisors, class 11 canines and Angle's class 1 molars. The second premolars are partially erupted.

shown the association of Maxillary lateral incisor microdontia with tooth agenesis [8] and supernumerary teeth with macrodontia [9].

Cho et al. [10] found a significant relationship between supernumerary premolars and dens evaginatus. Further, the presence of taurodontism and presence of dilaceration were significantly correlated [1].

There is lack of evidence in the literature reporting the concomitant presence of supernumerary teeth and the cusp of Carabelli [11]. Both these anomalies may have common genetic bases and/or developmental processes. Various theories exist to explain the occurrence of supernumerary teeth. However, heredity and genetics have been found to play a pivotal role in the etiology of dental anomalies of number and its increased recurrence in families [3,4]. A dominant autosomal trait has been suggested, with incomplete penetration in some generations and $\mathrm{X}$ chromosome linked inheritance due to the higher prevalence among males. The ratio of male to female is $2: 1[5,12]$. Regarding the aetiology of the cusps of carabelli, it is believed that the PAX and MSX genes are responsible for the extra cusps which result in the abnormal shape of the teeth [9].

Problems associated with supernumerary teeth include; failure of eruption of permanent teeth, displacement, crowding and pathology [13]. Management of supernumerary teeth depends on the type and position of the supernumerary teeth and on its effect or potential effect on adjacent teeth, therefore two options exist; either removal of the supernumerary tooth or monitoring the tooth without its removal [13]. On the other hand, the cusps of Carabelli have never been reported to interfere with the occlusion [6], this is in agreement with our findings, in which the patient initially presented with class 1 molar relationship bilaterally.
In this case report, the patient had a palatally erupted mesiodens that caused rotation of the neighboring upper right central incisor. This is in line with the findings of Nazif et al. [14] in which their study showed that $80 \%$ of mesiodens were palatally positioned behind the upper central incisors.

Moreover, the patient was of African descent and had prominent "positive cusps" of Carabelli which were separated from the parent molar by a well accentuated curved groove. The presence of these prominent cusps are consistent with the findings of Alvesalo [15] who reported that the "positive cusp" of Carbelli can be detected in Africans, although it is more frequently found in Europeans. The cusps of Carabelli are most commonly detected bilaterally, and palatal to the mesiopalatal cusps of the upper first permanent molars, $[6,15]$ this bilateralism was in agreement with our findings.

\section{Conclusion}

Sufficient information on concomitant dental anomalies especially supernumerary teeth and the cusps of Carabelli are not available in the literature. These anomalies are considered to have common genetic bases and/or developmental processes. Further research on this hypothesis is required.

\section{References}

1. Sener S, Bozdag G, Ünlü N. (2011) Presence, distribution, and association of dental anomalies: a clinical and radiographical study. Clinical Dentistry and Research 35:43-52.

2. Baccetti T (1998) A controlled study of associated dental anomalies. Angle Orthod 68 267-274. [Crossref]

3. Lara TS, Lancia M, da Silva Filho OG, Garib DG, Ozawa TO (2013) Prevalence of mesiodens in orthodontic patients with deciduous and mixed dentition and its association with other dental anomalies. Dental Press J Orthod 18: 93-99. [Crossref]

4. Peck S (2009) Dental Anomaly Patterns (DAP). A new way to look at malocclusion Angle Orthod 79: 1015-1016. [Crossref]

5. Yordanova G, Dinkova M (2014) Prevalence and Clinical Manifestation of Mesiodens IJSR 3:1665-1668.

6. Falomo OO (2002) The cusp of Carabelli: frequency, distribution, size and clinica significance in Nigeria. West Afr J Med 21: 322-324. [Crossref]

7. Cakan DG, Ulkur F, Taner T (2013) The genetic basis of dental anomalies and its relation to orthodontics. Eur J Dent 7: S143-147. [Crossref]

8. Garib DG, Alencar BM, Lauris JR, Baccetti T (2010) Agenesis of maxillary lateral incisors and associated dental anomalies. Am J Orthod Dentofacial Orthop 137: 732 [Crossref]

9. Brook AH (1984) A unifying aetiological explanation for anomalies of human tooth number and size. Arch Oral Biol 29: 373-378.

10. Cho SY, Ki Y, Chu V, Chan J (2006) Concomitant developmental dental anomalies in Chinese children with dens evaginatus. Int J Paediatr Dent 16: 247-251. [Crossref]

11. Lorena SC, Oliveira DT, Odellt EW (2003) Multiple dental anomalies in the maxillary incisor region. J Oral Sci 45: 47-50. [Crossref]

12. Colak H, Uzgur R, Tan E, Hamidi MM, Turkal M, et al. (2013) Investigation of prevalence and characteristics of mesiodens in a non-syndromic 11256 dental outpatients. Eur Rev Med Pharmacol Sci 17: 2684-2689. [Crossref]

13. Garvey MT, Barry HJ, Blake M (1999) Supernumerary teeth--an overview of classification, diagnosis and management. J Can Dent Assoc 65: 612-616. [Crossref]

14. Nazif MM, Ruffalo RC, Zullo T (1983) Impacted supernumerary teeth: a survey of 50 cases. J Am Dent Assoc 106: 201-204. [Crossref]

15. Alvesalo L, Nuutila M, Portin P (1975) The cusp of Carabelli. Occurrence in first upper molars and evaluation of its heritability. Acta Odontol Scand 33: 191-197. [Crossref]

Copyright: C2015 Elhag SBI. This is an open-access article distributed under the terms of the Creative Commons Attribution License, which permits unrestricted use, distribution, and reproduction in any medium, provided the original author and source are credited. 